\title{
A phase I/II study of gemcitabine- based chemotherapy plus curcumin for patients with gemcitabine-resistant pancreatic cancer.
}

\author{
AUTHOR(S): \\ Kanai, Masashi; Yoshimura, Kenichi; Asada, Masanori; \\ Imaizumi, Atsushi; Suzuki, Chihiro; Matsumoto, Shigemi; \\ Nishimura, Takafumi; ... Chiba, Tsutomu; Guha, Sushovan; \\ Aggarwal, Bharat B
}

\section{CITATION:}

Kanai, Masashi ...[et al]. A phase I/II study of gemcitabine-based chemotherapy plus curcumin for patients with gemcitabine-resistant pancreatic cancer.. Cancer chemotherapy and pharmacology 2011, 68(1): 157-164

\section{ISSUE DATE:}

2011-07

URL:

http://hdl.handle.net/2433/143578

\section{RIGHT:}

The final publication is available at www.springerlink.com; This is not the published version. Please cite only the published version.; この論文 は出版社版でありません。引用の際には出版社版をご確認ご利用くだ さい。 


\section{A Phase I/II Study of Complementary Therapy Using Curcumin for Patients with Gemcitabine-Resistant Pancreatic Cancer}

Masashi Kanai $^{{ }^{*}}$, Kenichi Yoshimura ${ }^{2}$, Masanori Asada ${ }^{3}$, Atsushi Imaizumi ${ }^{4}$, Chihiro Suzuki ${ }^{2}$, Shigemi Matsumoto ${ }^{1}$, Takafumi Nishimura ${ }^{1}$, Yukiko Mori ${ }^{1}$, Toshihiko Masui ${ }^{5}$, Yoshiya Kawaguchi $^{5}$, KazuhiroYanagihara ${ }^{1}$, ShujiroYazumi ${ }^{3}$, Tsutomu Chiba ${ }^{1,6}$, Sushovan Guha ${ }^{7}$, Bharat B. Aggarwal ${ }^{8}$

1) Outpatient Oncology Unit, Kyoto University Hospital, Kyoto, Japan

2) Translational Research Center, Kyoto University Hospital, Kyoto, Japan

3) Kitano Hospital, Osaka, Japan

4) Theravalues Corporation, Tokyo, Japan

5) Department of Surgery, Graduate School of Medicine, Kyoto University Hospital, Kyoto, Japan

6) Department of Gastroenterology and Hepatology, Kyoto University Hospital, Kyoto, Japan

7) Department of Gastrointestinal Medicine and Nutrition, MD Anderson Cancer Center, Houston, Texas, USA

8) Department of Experimental Therapeutics, MD Anderson Cancer Center, Houston, Texas, USA

${ }^{*}$ Corresponding author: Kyoto University Hospital, 54 Shogoin-Kawahara-cho, Sakyo-ku, Kyoto, 606-8507, Japan 
Tel.: +81-75-751-4770; Fax: +81-75-751-4772

E-mail:kanai@kuhp.kyoto-u.ac.jp 


\section{Abstract}

Purpose: Curcumin, a plant-derived natural polyphenol, could be a promising anti-cancer drug and shows synergic effects with cytotoxic agents. We evaluated the safety and feasibility of complementary therapy using curcumin with gemcitabine-based chemotherapy.

Methods: Gemcitabine-resistant patients with pancreatic cancer received $8 \mathrm{~g}$ oral curcumin daily in combination with gemcitabine-based chemotherapy. The primary endpoint was safety for phase I and feasibility of oral curcumin for phase II study.

Results: Twenty-one patients were enrolled. No dose-limiting toxicities were observed in the phase I study and oral curcumin $8 \mathrm{~g} /$ day was selected as the recommended dose for the phase II study. No patients were withdrawn from this study because of the intolerability of curcumin, which met the primary endpoint of the phase II study, and the median compliance rate of oral curcumin was $100 \%$ (Range $79-100 \%$ ). Median survival time after initiation of curcumin was 161 days (95\% confidence interval 109-223 days) and 1-year survival rate was $19 \%$ (4.4-41.4\%). Plasma curcumin levels ranged from 29 to $412 \mathrm{ng} / \mathrm{ml}$ in five patients tested. 
Conclusions: Complementary therapy using $8 \mathrm{~g}$ oral curcumin daily with gemcitabine-based chemotherapy was safe and feasible in patients with pancreatic cancer and warrants further investigation of its efficacy.

Key words: curcumin, gemcitabine, pancreatic cancer 


\section{Introduction}

Pancreatic cancer is one of the most lethal malignancies worldwide $[9,15]$. Although surgery remains the only modality to potentially cure this disease, most patients are diagnosed too late for curative resection. Even after potentially curative resection, this disease relapses in more than $80 \%$ of patients and incidence rates are almost coincident with mortality rates [18]. Over the past decade, gemcitabine has been widely used as a standard therapy for advanced pancreatic cancer. Gemcitabine has been proved to improve the median survival time and quality of life in advanced pancreatic cancer patients [4]; however, the prognosis of this disease remains dismal and the development of more effective therapy is urgently needed. Because pancreatic cancer patients often suffer from symptoms related to the cancer itself (e.g. fatigue, appetite loss, pain), it is also very important to maintain a balance between efficacy and quality of life in palliative chemotherapy for pancreatic cancer.

Curcumin is derived from turmeric (Curcuma longa) and is a natural polyphenol. Curcumin has long been used as a food, coloring agents or a traditional medicine. More and more data support the idea that this chemical could be a promising anti-cancer drug for a variety of tumors $[6,10,19,23]$. Preclinical studies demonstrated curcumin potentiates antitumor activity of gemcitabine against pancreatic cancer $[2,14]$. Human studies of curcumin have 
shown that this agent can be administered safely at doses of up to $12 \mathrm{~g} / \mathrm{day}[5,21]$ and some clinical benefit in patients with pancreatic cancer [7]. Thus, synergic effects of curcumin on gemcitabine in preclinical studies and safety of curcumin monotherapy in clinical studies have been reported; however, at the time of planning this clinical trial in 2008 , the safety and feasibility of curcumin in combination with gemcitabine-based chemotherapy had not been reported in a human study. Because the clinical condition of pancreatic cancer patients who failed gemcitabine-based chemotherapy was generally poor, we needed to evaluate whether these patients could tolerate a large amount of daily oral curcumin in combination with gemcitabine-based chemotherapy. Therefore we conducted this phase $\mathrm{I} / \mathrm{II}$ study to determine the safety and feasibility of oral curcumin in combination with gemcitabine-based chemotherapy in patients with pancreatic cancer. 


\section{Patients and methods}

\section{Eligibility criteria}

Patients with advanced pancreatic cancer who showed disease progression during gemcitabine-based chemotherapy and had no other effective treatment option were eligible if they met the following criteria: histological or radiological confirmation; age $\geq 20$ years; Eastern Cooperative Oncology Group (ECOG) performance status of $0-1$; bone marrow function (neutrophil count $\geq 1500 / \mathrm{mm}^{3}$ and platelet count $\geq 100,000 / \mathrm{mm}^{3}$ ), liver function (total bilirubin $\leq 3$ times the upper limit of normal (ULN) and aspartate aminotransferase/alanine aminotransferase (AST/ALT) $\leq 5$ times ULN) and renal function (creatinine $\leq 1.5 \mathrm{mg} / \mathrm{dL}$ ); adequate oral intake; and provided written informed consent. A criterion of neutrophil count /platelet count was amended to $\geq 1000 / \mathrm{mm}^{3} / \geq 50,000 / \mathrm{mm}^{3}$, respectively, after confirming safety of curcumin in phase I study. Exclusion criteria included: history of severe drug allergy; pregnancy or lactation; and other severe comorbid diseases.

This phase I/II study (UMIN ID 000001386) was conducted in two institutions in Japan. The protocol was approved by the institutional review board at each institution and patient registration and data management were conducted in an independent data center at Translational Research Center, Kyoto University Hospital. All procedures were performed in accordance with the 1964 Declaration of Helsinki. 


\section{Curcumin}

Curcumin was courteously provided by the Sabinsa Corporation (Piscataway, NJ, USA) in microbead form. One gram of curcuminoids consisted of $900 \mathrm{mg}$ of curcumin, $80 \mathrm{mg}$ of desmethoxycurcumin, and $20 \mathrm{mg}$ of bisdesmethoxycurcumin, which was confirmed by high-performance liquid chromatography tandem mass spectrometry (HPLC-MS/MS) as reported previously [7].

\section{Treatment}

As an initial dose level, oral curcumin daily with a dose of $8 \mathrm{~g}$ was chosen according to the previous human studies [5, 7, 21]. Oral curcumin was added to the gemcitabine-based chemotherapy (19 patients received gemcitabine/S-1 combination therapy and two patients received gemcitabine monotherapy). Patients were allowed to take $8 \mathrm{~g}$ of curcumin separately at their own convenience. The same dose and schedule of gemcitabine-based chemotherapy were applied as used before enrollment onto this study. After the initiation of curcumin intake, the dose and schedule of gemcitabine-based chemotherapy was adjusted at the discretion of individual physicians according to the adverse events observed in the previous cycle. Dose-limiting toxicity (DLT) for the phase I study was defined as follows: Grade 4 leucopenia; Grade 4 neutropenia; Grade 3 or more thrombocytopenia; 
non-hematological toxicity of Grade 3 or more (except for the abnormal blood test); patient refusal due to the intolerability of curcumin intake. No dose escalation was planned and dose de-escalation to $6 \mathrm{~g} /$ day was pre-planned if more than one DLT among three assessable patients or more than two DLTs among six assessable patients were observed. Chemotherapy was suspended until recovery if neutrophil count was $<1000 / \mathrm{mm}^{3}$, platelet count was $<70,000 / \mathrm{mm}^{3}$, total bilirubin was $>3.0 \mathrm{mg} / \mathrm{dL}$, AST/ALT was $>150 \mathrm{U} / \mathrm{L}$, creatinine was $>1.5 \mathrm{mg} / \mathrm{dL}$, stomatitis/diarrhea was Grade 2 or higher, skin rash was Grade 3 or higher, or there was a fever $\left(>38^{\circ} \mathrm{C}\right)$ due to infection. During the suspension of gemcitabine-based chemotherapy, curcumin intake was also suspended. The study treatment was continued until intolerability of curcumin intake, unacceptable toxicity related to treatment, patient refusal, or discontinuation of gemcitabine-based chemotherapy because of deterioration of general condition due to disease progression occurred.

\section{Pretreatment and follow-up evaluation}

Pretreatment evaluation included obtaining the patient's medical history and performing a physical examination, imaging using contrast-enhanced computed tomography (CT) or magnetic resonance imaging (MRI), a complete blood cell count, and serum biochemical tests. Physical examinations and blood tests were scheduled on the day of gemcitabine administration. Carcinoembryonic antigen (CEA) and carbohydrate antigen 19-9 (CA19-9) 
were measured every month. Toxicity was evaluated using the National Cancer Institute Common Toxicity Criteria version 3.0 [25].

\section{Sample preparation and measurement of plasma curcumin levels by HPLC-MS/MS}

Despite the use of doses of curcumin as high as $8 \mathrm{~g} /$ day, previous studies reported very little free curcumin is found in patient plasma samples [21]. Instead, curcumin is present in plasma in conjugated (glucuronide and sulfate) forms, which necessitates appropriate enzymatic hydrolysis of the plasma before detection of free curcumin $[7,26]$. In the present study we measured plasma curcumin levels in five patients who provided written informed consent for blood draws for this purpose. A $0.1 \mathrm{~mL}$ aliquot of each plasma sample was transferred to a $10 \mathrm{~mL}$ glass tube and then $0.11 \mathrm{~mL}$ of $0.1 \mathrm{M}$ sodium acetate buffer $(\mathrm{pH} 5.0)$ containing $1000 \mathrm{U} \beta$-glucuronidase was added. The resulting solutions were incubated to hydrolyze the curcumin conjugates at $37^{\circ} \mathrm{C}$ for $1 \mathrm{~h}$. After $10 \mu \mathrm{L}$ of Internal Standard (IS) working solution $(500 \mathrm{ng} / \mathrm{mL})$ was added, $0.5 \mathrm{~mL}$ of chloroform as extraction solvent was added. The sample was vortexed for $1 \mathrm{~min}$ followed by ultrasonic vibrations for $15 \mathrm{~min}$ and then centrifugation at $1610 \times g$ for $5 \mathrm{~min}$. The organic layer was transferred to a $1 \mathrm{~mL}$ glass tube and evaporated to dryness using a centrifuge concentrator. The dried extract was reconstituted in $100 \mu \mathrm{L}$ of $50 \%$ acetonitrile containing $0.05 \%$ formic acid (FA) and then 
centrifugated at $7700 \times g$ for $10 \mathrm{~min}$. A $10 \mu \mathrm{L}$ aliquot of supernatant of reconstituted sample solution was injected into the chromatographic system.

The HPLC-MS/MS system consisted of a Prominence micro-LC system (Shimadzu, Kyoto, Japan) and an API 3200 tandem mass spectrometer (Applied Biosystems, Carlsbad, CA, USA) with (+) electrospray ionization (ESI). Samples were put through an Atlantis T3 $(2.1 \times 150 \mathrm{~mm}, 3 \mu \mathrm{m})$ (Waters, Milford, USA) C-18 separation column using a gradient of binding solvent $(0.05 \% \mathrm{FA} /$ water $)$ and elution solvent $(0.05 \% \mathrm{FA} /$ acetonitrile $)$ at a flow rate of $0.2 \mathrm{~mL} / \mathrm{min}$ and a column temperature of $40^{\circ} \mathrm{C}$. Separation of samples was conducted by a 35 min linear gradient (5-95\% elution solvent). The mass spectrometer was operated under multiple reaction monitoring (MRM) mode with collision energy of $23 \mathrm{eV}$ for curcumin and $33 \mathrm{eV}$ for mepronil. The transitions (precursor to product) monitored were $\mathrm{m} / \mathrm{z} 369 \rightarrow 285$ for curcumin and $270 \rightarrow 119$ for mepronil. Chromatograms were integrated using ANALYST software, version 1.5.Stock solutions of curcumin and mepronil were prepared at a concentration of $1000 \mathrm{ng} / \mathrm{mL}$ in methanol. The stock solution of mepronil was further diluted with $55 \%$ methanol to prepare a calibration standard at a concentration of $100 \mathrm{ng} / \mathrm{mL}$. The stock solution of curcumin was further diluted with $62 \%$ methanol to prepare a calibration standard at a concentration of $200 \mathrm{ng} / \mathrm{mL}$. Curcumin solution $(200 \mathrm{ng} / \mathrm{mL})$ was diluted with $50 \%$ methanol to prepare the following standard solutions: $0.4,0.8,1.6,3.1,6.3,12.5,25.0$, 
50.0 , and $100.0 \mathrm{ng} / \mathrm{mL}$. These solutions were mixed with IS solution $(100 \mathrm{ng} / \mathrm{mL})$ at a ratio of 1:1 to prepare IS-containing calibration samples of $0.2-100.0 \mathrm{ng} / \mathrm{mL}$ (curcumin) and 50 $\mathrm{ng} / \mathrm{mL}$ (mepronil). Stock solution (1000 ng/mL) of mepronil was further diluted with methanol to prepare the IS working solution at a concentration of $500 \mathrm{ng} / \mathrm{mL}$.

\section{Statistical analysis}

The primary endpoint was safety for the phase I study and treatment completion rate (TCR) of oral curcumin daily at dose of $8 \mathrm{~g}$ for the phase II study. TCR was defined as the percentage of patients after excluding those who were withdrawn from this study because of the intolerability of curcumin. The secondary endpoints for phase II were response rate,overall survival (OS) and compliance rate of curcumin. We considered if less than $50 \%$ of patients could tolerate complementary therapy using curcumin, this therapy was not worth for further evaluation. If $80 \%$ or more patients could continue this therapy without any clinically relevant toxicity, this therapy was considered to be worth for further evaluation of its efficacy. Therefore, a sample size of 21 patients for phase II was determined to reject the null hypothesis of a TCR of $50 \%$ under the expectations of $80 \%$ TCR with a significance level of 0.05 and a power of $80 \%$. Among patients with measurable target lesions, the objective response rate was evaluated according to Response Evaluation Criteria in Solid Tumors (RECIST) version 1.0 [24]. OS was defined as the time from initiation of 
complementary therapy using curcumin to death from any cause or the final follow-up, and OS rate was calculated using the Kaplan-Meier method. The final analysis was conducted in April 2010. All analyses were conducted on an intention-to-treat basis and were performed using SAS version 9.2 (SAS Institute, Cary, NC, USA). 


\section{Results}

\section{Patient characteristics}

Twenty-one patients were enrolled between September 2008 and August 2009. The patient characteristics are shown in Table 1. The median age was 67 years (range $44-79$ years) and 13 patients $(62 \%)$ were men. Seven of the 21 patients $(33 \%)$ experienced recurrent disease after undergoing curative surgery and three patients had a history of radiotherapy. All the patients had a history of receiving gemcitabine and S-1. Oral curcumin was added to gemcitabine/S-1 combination therapy in 19 patients (90\%) and gemcitabine monotherapy in two patients (10\%).

\section{Toxicity}

In the phase I study, safety of oral curcumin taken daily at dose of $8 \mathrm{~g}$ in combination with gemcitabine-based chemotherapy was evaluated. Since the first three assessable patients completed their first cycle without a DLT at $8 \mathrm{~g} /$ day, we selected this amount as the recommended dose for the following phase II study. Overall adverse events are summarized in Table 2. The most common grade 3-4 hematological toxicity was neutropenia (38\%) and grade 3-4 non-hematological toxicity was fatigue (10\%), both of which were likely to be attributed to the gemcitabine-based chemotherapy or disease progression and considered to be irrelevant to curcumin. Other Grade 3-4 non-hematological adverse events were a 
drowsiness $(n=1)$, an anorexia $(n=1)$, an obstruction of gastrointestinal tract $(n=1)$, and an edema $(n=1)$, all of which were also attributed to disease progression.

\section{Treatment completion rate and compliance rate of curcumin}

No patients were withdrawn from this study because of the intolerability of curcumin, yielding a TCR of $100 \%$ (95\% confidence interval $(\mathrm{Cl}) 84-100 \% ; P<0.001$ under the null hypothesis of a $50 \%$ TCR). At the time of final analysis in April 2010, two patients were still on protocol treatment and the reasons for discontinuation of protocol treatment were disease progression ( $n=12)$, adverse events unrelated to curcumin intake $(n=3)$, judgment of physician $(n=1)$, referral to another hospital $(n=1)$, patient's request $(n=1)$ and protocol violation ( $n=1)$. Compliance rate of curcumin is summarized in Table 3 . In spite of the high amount required to be taken, 19 patients (90\%) were able to take more than $90 \%$ of the curcumin scheduled in this clinical trial.

\section{Efficacy}

Seventeen patients $(81 \%)$ died during the study period. The median overall survival time was 161 days $(95 \% \mathrm{Cl} 109-223$ days) and 1-year survival rate was $19 \%(95 \% \mathrm{Cl}$ 4.4-41.4\%)(Figure 1). Among eighteen evaluable patients, no patients experienced a partial or complete response and five patients (28\%) demonstrated stable disease according to RECIST. Median time to treatment failure was 71 days (95\% CI 58-126 days)(Figure 2). 


\section{Curcumin pharmacology}

Plasma curcumin levels were measured in five patients. We measured curcumin levels following digestion of plasma with combined glucuronidase and sulfatase enzymes. The data on plasma curcumin levels and information about duration of curcumin intake and time of blood draw after final curcumin intake are summarized in Table 4. Except for one patient who demonstrated a plasma curcumin level of $412 \mathrm{ng} / \mathrm{ml}$, curcumin levels ranged from 29 to $91 \mathrm{ng} / \mathrm{ml}$, which was comparable with the previous study [7, 21]. 


\section{Discussion}

Curcumin has been reported to modulate a variety of molecules which play an important role in cancer progression. One of the major targets of curcumin is NF-kB, which regulates the expression of a number of genes involved in antiapoptosis (Bcl-2, Bcl-xL), proliferation (cyclin D1, c-myc), angiogenesis (vascular endothelial growth factor (VEGF), interleukin-8), and invasion (matrix metalloproteinases) $[1,11,13,16]$. Several preclinical studies have also reported the synergic effect of curcumin in combination with cytotoxic agents. Synergic inhibitory effects of curcumin and 5-fluorouracil on the growth of cancer cell lines have been demonstrated [8, 12]. Vinorelbine-mediated apoptosis is also enhanced by curcumin in squamous lung cancer cell line [20]. Kunnumakkara et al. demonstrated that curcumin potentiates the antitumor effects of gemcitabine in pancreatic cancer and suppresses NF-kB-regulated genes in vitro and in vivo [14]; however, we have no data about the safety and feasibility of curcumin in combination with gemcitabine-based chemotherapy in human studies and we conducted current study to evaluate whether pancreatic patients could tolerate large amount of daily oral curcumin in combination with gemcitabine-based chemotherapy. The toxicity profile of this study was comparable with that observed in pancreatic cancer patients treated with gemcitabine/S-1 combination therapy [29]. Therefore, we considered adding oral curcumin to gemcitabine-based chemotherapy did not increase 
the risk of clinically relevant toxicity. No patients were withdrawn from this study because of the intolerability of curcumin and a high compliance rate was achieved in spite of the poor clinical condition after failure of gemcitabine-based chemotherapy. In fact, the median compliance rate of oral curcumin was 100\% (range 79-100\%), as shown in Table 3, which strongly supported the minimal toxicity of this agent in cancer patients who were receiving concomitant chemotherapy. Furthermore, cumulative toxicity of curcumin was not observed in this study and four patients could continue curcumin intake for more than 6 months without any significant toxicity, which supports the safety of this agent for long-term use. Since pancreatic cancer patients suffer from symptoms related to cancer itself, the low toxicity of this agent is a great advantage for its clinical application in cancer treatment. Some previous clinical studies indicated the risk of diarrhea with curcumin intake [10, 21]. In our study, among four cases of grade 1 diarrhea, two cases could have been attributed to curcumin, but this did not interrupt curcumin intake or gemcitabine-based chemotherapy. We speculated that allowing patients to take curcumin separately reduced the risk of osmotic diarrhea caused by large amounts of curcumin taken at once. Another possible explanation was that patients with pancreatic cancer often suffered from constipation due to peritonitis carcinomatosa or side effect of taking morphine and these backgrounds might have attenuated the risk of diarrhea. In consistent with our current study, Bayet-Robert et al. 
recently conducted phase I study of docetaxel plus curcumin in breast cancer patients and reported the safety of oral curcumin at a dose of $6 \mathrm{~g} /$ day for 7 consecutive days every 3 weeks [3].

As Oettle et al. reported that median survival time after failure of first-line gemcitabine therapy was only 10 weeks in patients receiving best supportive care alone [17], the prognosis of pancreatic cancer patients who failed gemcitabine-based chemotherapy was very poor. Therefore, a median survival time of 161 days (95\% Cl 109-223 days) and a 1-year survival rate of $19 \%(95 \% \mathrm{Cl} 4.4-41.4 \%)$ in our current study were encouraging and warranted further investigation. Interestingly, several patients reported an improvement of cancer- or chemotherapy-related symptoms (e.g. fatigue, pain, constipation) after the initiation of curcumin intake. Unfortunately the quality-of-life score was not included in the pre-specified endpoints in our current study and these changes might be solely attributed to placebo effects; however, data from several basic studies support our current observation. Curcumin has been shown to improve depressive-like behaviors in mice with an increase in serotonin, noradrenaline, and dopamine levels in the brain $[27,28]$ or attenuate hyperalgesia in a mouse model of neuropathic pain [22]. It is very important to maintain quality of life in palliative chemotherapy for pancreatic cancer and the improvement of cancer- or chemotherapy-related symptoms could increase the compliance to chemotherapy, 
which largely affects the efficacy of chemotherapy and overall survival. More clinical trials are needed to determine the efficacy of curcumin from viewpoint of quality of life in cancer patients.

Plasma curcumin levels were measured in five patients. Except for one patient, our current results were almost consistent with a previous study reporting that steady-state curcumin level ranged from 22 to $41 \mathrm{ng} / \mathrm{ml}$ [7]. Furthermore, current results demonstrated a cumulative increase in curcumin levels was unlikely after long-term intake. Poor bioavailability is the major weak point of curcumin when considering its clinical application. Since basic studies suggested that a microgram range of curcumin in target tissue is necessary to achieve anti-cancer effects, many researchers are focusing on improving the bioavailability of curcumin to get more benefits from this promising agent. Recently, pulverized curcumin was developed in Japan (Theravalues Corporation, Tokyo, Japan) to improve the agent's bioavailability. If we could achieve higher plasma curcumin levels, we could expect more benefits from curcumin in the treatment of cancer patients and we are now planning clinical trials to evaluate the efficacy of this newly developed curcumin.

In conclusion, our data demonstrated that administration of oral curcumin in combination with gemcitabine-based chemotherapy is safe and well-tolerated in pancreatic cancer 
patients. More studies are now underway to establish the efficacy of this promising agent in cancer treatment.

Acknowledgement

We thank Hiroe Tada and Miyuki Niimi for their contributions to data management, Emi

Shimada and Dr Vladimir Badmaev for their contributions to curcumin shipment.

\section{Grant support}

This work was supported by the Grant-in-Aid for Young Scientists (21790661) from the Japan Society for the Promotion of Science, Japanese Research Foundation for Clinical Pharmacology and Smoking Research Foundation. 
Table 1. Patient characteristics $(n=21)$

\begin{tabular}{llc}
\hline Gender & Male & $13(62.0 \%)$ \\
& Female & $8(38.0 \%)$ \\
Age (years) & Median & 67 \\
& Range & $44-79$ \\
\hline Diagnosis & Histological confirmation & $19(90.0 \%)$ \\
\hline History of anti-cancer drugs & Gemcitabine & $2(10.0 \%)$ \\
\hline History of surgery & S-1 & $21(100.0 \%)$ \\
\hline History of radiotherapy & & $21(100.0 \%)$ \\
\hline Concomitant chemotherapy & Gemcitabine/S-1 & $7(33 \%)$ \\
\hline & Gemcitabine & $3(14 \%)$ \\
\hline
\end{tabular}


Table 2. Toxicity

\begin{tabular}{|c|c|c|c|c|c|c|}
\hline & Grade 1 & Grade 2 & Grade 3 & Grade 4 & $\geqq$ Grade 3 & $\begin{array}{c}\geqq \text { Grade } \\
1-4\end{array}$ \\
\hline Fatigue & 7 & 3 & 2 & 0 & $10 \%$ & $57 \%$ \\
\hline Anorexia & 5 & 2 & 1 & 0 & $5 \%$ & $38 \%$ \\
\hline Diarrhea & 4 & 0 & 0 & 0 & $0 \%$ & $19 \%$ \\
\hline $\begin{array}{l}\text { Hand-foot } \\
\text { rash }\end{array}$ & 4 & 0 & 0 & - & $0 \%$ & $19 \%$ \\
\hline Stomatitis & 3 & 0 & 0 & 0 & $0 \%$ & $14 \%$ \\
\hline Nausea & 2 & 0 & 0 & 0 & $0 \%$ & $10 \%$ \\
\hline Vomiting & 1 & 0 & 0 & 0 & $0 \%$ & $5 \%$ \\
\hline Leukocytes & 1 & 5 & 7 & 0 & $33 \%$ & $62 \%$ \\
\hline Neutrophil & 0 & 4 & 8 & 0 & $38 \%$ & $57 \%$ \\
\hline Hemoglobin & 3 & 9 & 4 & 0 & $19 \%$ & $76 \%$ \\
\hline Platelets & 4 & 3 & 2 & 0 & $10 \%$ & $43 \%$ \\
\hline Bilirubin & 7 & 2 & 1 & 1 & $10 \%$ & $52 \%$ \\
\hline AST & 14 & 0 & 0 & 0 & $0 \%$ & $67 \%$ \\
\hline ALT & 7 & 2 & 0 & 0 & $0 \%$ & $43 \%$ \\
\hline Creatinine & 3 & 1 & 0 & 0 & $0 \%$ & $19 \%$ \\
\hline Albumin & 9 & 9 & 0 & 0 & $0 \%$ & $86 \%$ \\
\hline ALP & 11 & 4 & 0 & 0 & $0 \%$ & $71 \%$ \\
\hline $\begin{array}{l}\text { Others } \\
\text { ( } \geqq \text { Grade 3) }\end{array}$ & - & - & 4 & 0 & $19 \%$ & - \\
\hline
\end{tabular}




\section{Table 3. Compliance rate}

\begin{tabular}{lr} 
Compliance Rate $(\boldsymbol{n = 2 1 )}$ & \\
\hline$<0.70$ & 0 \\
$\geq 0.70,<0.80$ & 1 \\
$\geq 0.80,<0.90$ & 1 \\
$\geq 0.90,<0.95$ & 1 \\
$\geq 0.95,<1.00$ & 4 \\
1.00 & 14 \\
\hline Compliance rate $\geq 0.90$ & $90 \%$ \\
$(95 \%$ Cl) & $(70-99 \%)$
\end{tabular}


Table 4. Plasma curcumin levels and patient information

\begin{tabular}{|c|c|c|c|c|c|}
\hline & $\begin{array}{c}\text { Age } \\
\text { (years) }\end{array}$ & Gender & $\begin{array}{c}\text { Duration of } \\
\text { curcumin intake }\end{array}$ & $\begin{array}{l}\text { Plasma curcumin } \\
\text { levels (ng/ml) }\end{array}$ & $\begin{array}{l}\text { Time of blood draw after } \\
\text { final curcumin intake } \\
\text { (hours) }\end{array}$ \\
\hline Case 1 & 69 & Female & 14 months & 29 & 24 \\
\hline Case 2 & 75 & Male & 4 months & 55 & 4 \\
\hline Case 3 & 67 & Female & 6 months & 85 & 1 \\
\hline Case 4 & 75 & Female & 6 months & 91 & 9 \\
\hline Case 5 & 70 & Male & 3 months & 412 & 4 \\
\hline
\end{tabular}


Figure 1. Overall survival $(n=21)$

MST, median survival time.

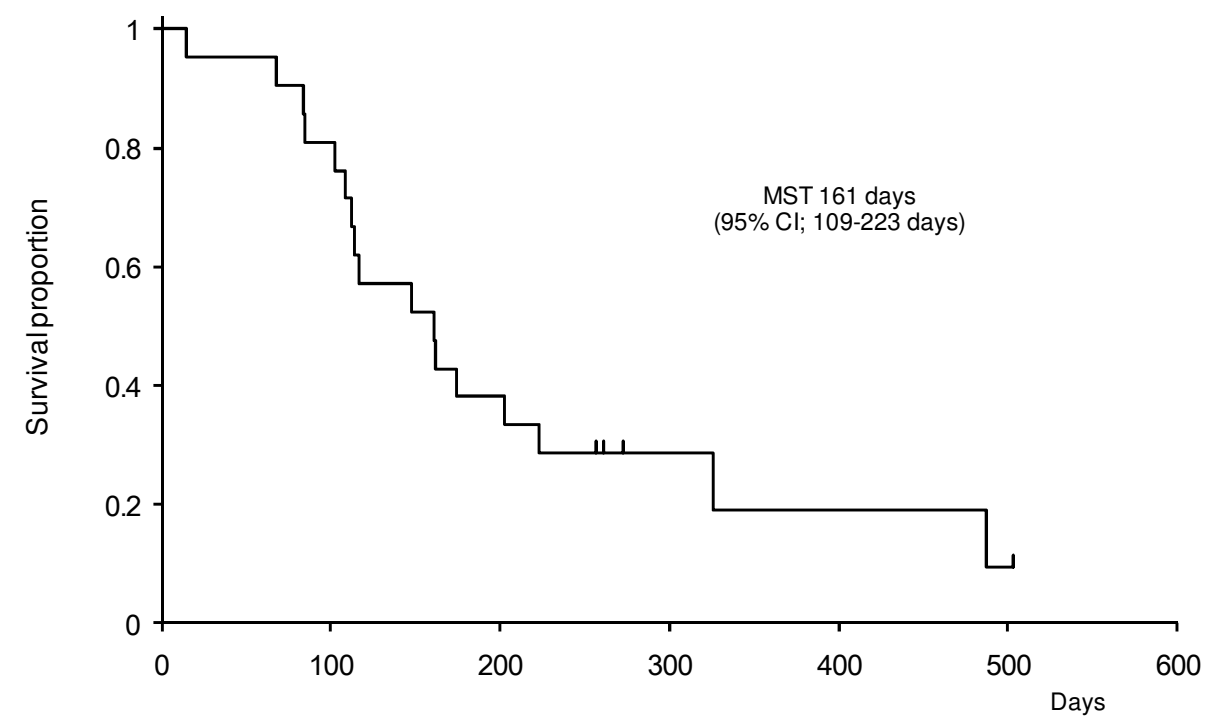


Figure 2. Time to treatment failure $(n=21)$

TTF, time to treatment failure

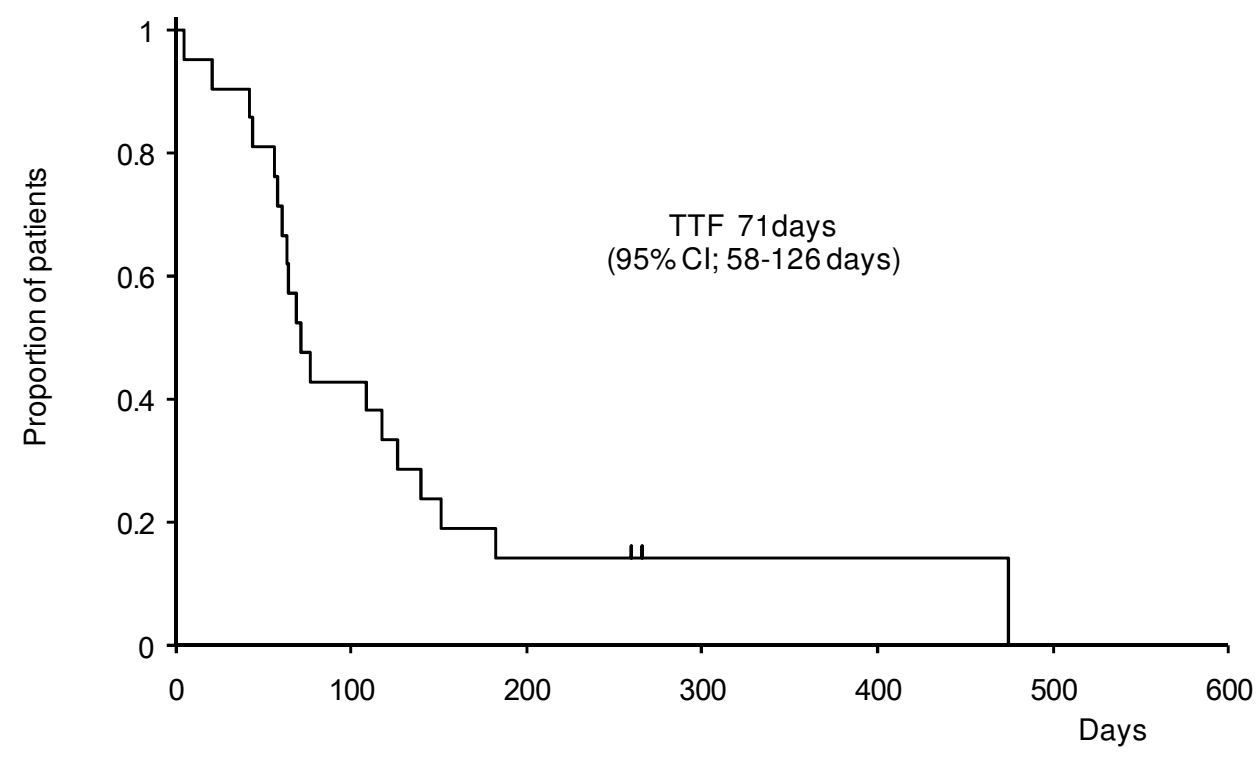




\section{References}

[1] Aggarwal S, Ichikawa H, Takada Y, Sandur SK, Shishodia S, Aggarwal BB (2006)

Curcumin (diferuloylmethane) down-regulates expression of cell proliferation and

antiapoptotic and metastatic gene products through suppression of IkappaBalpha kinase

and Akt activation. Mol Pharmacol 69: 195-206

[2] Ali S, Ahmad A, Banerjee S, Padhye S, Dominiak K, Schaffert JM, Wang Z, Philip

PA, Sarkar FH (2010) Gemcitabine sensitivity can be induced in pancreatic cancer cells

through modulation of miR-200 and miR-21 expression by curcumin or its analogue CDF.

Cancer Res 70: 3606-17

[3] Bayet-Robert M, Kwiatkowski F, Leheurteur M, Gachon F, Planchat E, Abrial C,

Mouret-Reynier MA, Durando X, Barthomeuf C, Chollet P (2010) Phase I dose escalation

trial of docetaxel plus curcumin in patients with advanced and metastatic breast cancer.

Cancer Biol Ther 9: 8-14

[4] Burris HA, 3rd, Moore MJ, Andersen J, Green MR, Rothenberg ML, Modiano MR,

Cripps MC, Portenoy RK, Storniolo AM, Tarassoff P, Nelson R, Dorr FA, Stephens CD, Von

Hoff DD (1997) Improvements in survival and clinical benefit with gemcitabine as first-line

therapy for patients with advanced pancreas cancer: a randomized trial. J Clin Oncol 15:

2403-13 
[5] Cheng AL, Hsu CH, Lin JK, Hsu MM, Ho YF, Shen TS, Ko JY, Lin JT, Lin BR, Ming-Shiang W, Yu HS, Jee SH, Chen GS, Chen TM, Chen CA, Lai MK, Pu YS, Pan MH, Wang YJ, Tsai CC, Hsieh CY (2001) Phase I clinical trial of curcumin, a chemopreventive agent, in patients with high-risk or pre-malignant lesions. Anticancer Res 21: 2895-900 [6] Corson TW, Crews CM (2007) Molecular understanding and modern application of traditional medicines: triumphs and trials. Cell 130: 769-74

[7] Dhillon N, Aggarwal BB, Newman RA, Wolff RA, Kunnumakkara AB, Abbruzzese JL, Ng CS, Badmaev V, Kurzrock R (2008) Phase II trial of curcumin in patients with advanced pancreatic cancer. Clin Cancer Res 14: 4491-9

[8] Du B, Jiang L, Xia Q, Zhong L (2006) Synergistic inhibitory effects of curcumin and 5-fluorouracil on the growth of the human colon cancer cell line HT-29. Chemotherapy 52: 23-8

[9] Eckel F, Schneider G, Schmid RM (2006) Pancreatic cancer: a review of recent advances. Expert Opin Investig Drugs 15: 1395-410

[10] Golombick T, Diamond TH, Badmaev V, Manoharan A, Ramakrishna R (2009) The potential role of curcumin in patients with monoclonal gammopathy of undefined significance--its effect on paraproteinemia and the urinary N-telopeptide of type I collagen bone turnover marker. Clin Cancer Res 15: 5917-22 
[11] Kanai M, Konda Y, Nakajima T, Izumi Y, Takeuchi T, Chiba T (2001) TGF-alpha inhibits apoptosis of murine gastric pit cells through an NF-kappaB-dependent pathway. Gastroenterology 121: 56-67

[12] Koo JY, Kim HJ, Jung KO, Park KY (2004) Curcumin inhibits the growth of AGS human gastric carcinoma cells in vitro and shows synergism with 5-fluorouracil. J Med Food 7: $117-21$

[13] Kumar A, Dhawan S, Hardegen NJ, Aggarwal BB (1998) Curcumin (Diferuloylmethane) inhibition of tumor necrosis factor (TNF)-mediated adhesion of monocytes to endothelial cells by suppression of cell surface expression of adhesion molecules and of nuclear factor-kappaB activation. Biochem Pharmacol 55: 775-83

[14] Kunnumakkara AB, Guha S, Krishnan S, Diagaradjane P, Gelovani J, Aggarwal BB (2007) Curcumin potentiates antitumor activity of gemcitabine in an orthotopic model of pancreatic cancer through suppression of proliferation, angiogenesis, and inhibition of nuclear factor-kappaB-regulated gene products. Cancer Res 67: 3853-61

[15] Matsuno S, Egawa S, Fukuyama S, Motoi F, Sunamura M, Isaji S, Imaizumi T, Okada S, Kato H, Suda K, Nakao A, Hiraoka T, Hosotani R, Takeda K (2004) Pancreatic Cancer Registry in Japan: 20 years of experience. Pancreas 28: 219-30

[16] Mukhopadhyay A, Banerjee S, Stafford LJ, Xia C, Liu M, Aggarwal BB (2002) 
Curcumin-induced suppression of cell proliferation correlates with down-regulation of cyclin

D1 expression and CDK4-mediated retinoblastoma protein phosphorylation. Oncogene 21:

$8852-61$

[17] Oettle H PU, Stieler J et al (2005) Oxaliplatin/follnic acid/5-fluorouracil [24h] (OFF) plus best supportive care versus best supportive care alone (BSC) in secondary-line therapy of gemcitabine-refractory advanced pancreatic cancer (CONKO 003) Proc Am Soc Clin

Oncol 23

[18] Pisters PW, Wolff RA, Crane CH, Evans DB (2005) Combined-modality treatment for operable pancreatic adenocarcinoma. Oncology (Williston Park) 19: 393-404, 409; discussion 409-10, 412-6

[19] Saif MW (2008) Is there a role for herbal medicine in the treatment of pancreatic cancer?. Highlights from the "44th ASCO Annual Meeting". Chicago, IL, USA. May 30 - June 3, 2008. JOP 9: 403-7

[20] Sen S, Sharma H, Singh N (2005) Curcumin enhances Vinorelbine mediated apoptosis in NSCLC cells by the mitochondrial pathway. Biochem Biophys Res Commun 331: $1245-52$

[21] Sharma RA, Euden SA, Platton SL, Cooke DN, Shafayat A, Hewitt HR, Marczylo TH, Morgan B, Hemingway D, Plummer SM, Pirmohamed M, Gescher AJ, Steward WP 
(2004) Phase I clinical trial of oral curcumin: biomarkers of systemic activity and compliance.

Clin Cancer Res 10: 6847-54

[22] Sharma S, Kulkarni SK, Agrewala JN, Chopra K (2006) Curcumin attenuates

thermal hyperalgesia in a diabetic mouse model of neuropathic pain. Eur $\mathrm{J}$ Pharmacol 536:

256-61

[23] Strimpakos AS, Sharma RA (2008) Curcumin: preventive and therapeutic properties in laboratory studies and clinical trials. Antioxid Redox Signal 10: 511-45

[24] Therasse P, Arbuck SG, Eisenhauer EA, Wanders J, Kaplan RS, Rubinstein L, Verweij J, Van Glabbeke M, van Oosterom AT, Christian MC, Gwyther SG (2000) New guidelines to evaluate the response to treatment in solid tumors. European Organization for Research and Treatment of Cancer, National Cancer Institute of the United States, National Cancer Institute of Canada. J Natl Cancer Inst 92: 205-16

[25] Trotti A, Colevas AD, Setser A, Rusch V, Jaques D, Budach V, Langer C, Murphy B, Cumberlin R, Coleman CN, Rubin P (2003) CTCAE v3.0: development of a comprehensive grading system for the adverse effects of cancer treatment. Semin Radiat Oncol 13: 176-81

[26] Vareed SK, Kakarala M, Ruffin MT, Crowell JA, Normolle DP, Djuric Z, Brenner DE (2008) Pharmacokinetics of curcumin conjugate metabolites in healthy human subjects. 
Cancer Epidemiol Biomarkers Prev 17: 1411-7

[27] Xu Y, Ku BS, Yao HY, Lin YH, Ma X, Zhang YH, Li XJ (2005) Antidepressant effects of curcumin in the forced swim test and olfactory bulbectomy models of depression in rats. Pharmacol Biochem Behav 82: 200-6

[28] Xu Y, Ku BS, Yao HY, Lin YH, Ma X, Zhang YH, Li XJ (2005) The effects of curcumin on depressive-like behaviors in mice. Eur J Pharmacol 518: 40-6

[29] Yamauchi J, Kanai M, Matsumoto S, Nishimura T, Yazumi S, Kami K, Kawaguchi Y, Yasuda H, Kitano T, Misawa A, Ishiguro H, Yoshikawa K, Yanagihara K, Fukushima M, Doi R, Chiba T (2008) Clinical outcome of gemcitabine/S-1 combination therapy for advanced pancreatic cancer. Pancreas $36: 327-8$ 